\section{Reacción distónica aguda a quinina}

\section{Sr. Director:}

La distonía es un trastorno del movimiento caracterizado por la contracción simultanea de músculos agonistas y antagonistas. Su etiología es diversa, existiendo un importante subgrupo debida a fármacos. Los neurolépticos son los fármacos mas frecuentemente implicados en la génesis de reacciones distónicas, asociados al bloqueo de los receptores dopaminérgicos a nivel de los núcleos caudado, putamen y globo pálido. Sin embargo, en ocasiones se ha descrito en relación con fármacos no antidopaminergicos $(1,2)$. Presentamos el caso de un paciente con distonía aguda coincidiendo con la administración de quinina intravenosa que creemos de interés por no haberse descrito anteriormente ningún caso en la literatura.

Se trata de un varón de 26 años, misionero, que tras estancia prolongada en Benín, zona de alta resistencia a cloroquina, acude a nuestro centro por fiebre termometrada de $40^{\circ}$, escalofríos y afectación del estado general. Ante la sospecha clínica de paludismo se instaura tratamiento oral con sulfato de quinina y doxiciclina. Por cuadro de intolerancia oral se decide administrar el fármaco de forma parenteral, en forma de formiato de quinina $500 \mathrm{mg}$ cada 8 horas en infusión lenta. Coincidiendo con la administración de quinina el paciente presentó en dos ocasiones cuadro de distonía oromandibular y en miembro superior izquierdo que cedió tras la retirada del fármaco y la administración de biperideno.

La quinina, alcaloide de la cinchona, fue el primer agente antipalúdico descrito (3). Actualmente su uso queda relegado para zonas con alta resistencia a cloroquina. La quinina presenta la peor relación terapéutico-tóxica de todos los antipalúdicos (4). Sus efectos colaterales son conocidos con el nombre de cinconismo, y consisten en tinnitus, hipoacusia, cefalea, disfonia, náuseas, vómitos y alteraciones visuales y son dosisdependiente y reversibles. Otros efectos colaterales menos frecuentes son rash cutáneo, angioedema, prurito, agranulocitosis, hipoglucemia, hepatitis y rara vez hemolisis masiva $(4,5)$. Por su efecto tipo curare sobre el músculo esquelético está contraindicado en la miastenia gravis y a su vez es usado en el tratamiento de los calambres nocturnos (6). Administrado en infusión intravenosa rápida puede producir shock por depresión miocárdica y vasodilatación periférica.
La asociación de antipalúdicos con reacciones distónicas agudas está escasamente recogido en la literatura, relacionándose en dichos casos con el uso de cloroquina $(2,4,5,7)$. No hemos encontrado en la literatura ningún caso en relación al uso de quinina.

El mecanismo por el cual la cloroquina produce la aparición de movimientos involuntarios anormales no está claro. Se sabe que la cloroquina presenta gran avidez por los tejidos con alto contenido en melanina, la cual es un producto derivado del metabolismo de la dopamina, y dada la similitud estructural entre ambas sustancias se piensa que la cloroquina presentaría a su vez gran afinidad por los tejidos ricos en dopamina, como es el sistema nigroestriado, y actuaría bloqueando los receptores dopaminérgicos provocando la aparición de movimientos involuntarios (7). Otros autores propugnan que sería debido a un efecto débil pero específico inhibidor sobre el sistema adrenérgico de la cloroquina (8). Por otra parte, también se postula que cloroquina actúa inhibiendo la captación de calcio iónico celular mediante su interacción con los fosfolípidos de membrana produciendo el desplazamiento del calcio de las mismas; esta acción sobre las neuronas del sistema nigroestriado podría dar lugar a una reducción en los niveles de dopamina a nivel del cuerpo estriado y a la aparición de distonía (8). No obstante, aunque desconocemos la causa última de la reacción distona por antipalúdicos, sí se puede postular que estos mismos mecanismos propuestos serían aplicables a la quinina al tratarse de dos moléculas con cierta similitud en su composición.

Ma C. Fernández-Moreno, L. Castilla-Guerra', J. Enrique Cor$z^{2}$, E. Cuartero, $M^{\mathrm{a}}$ D. Torrecillas, B. Cueli, $\mathbf{M}^{\mathrm{a}} \mathrm{D}$. Jiménez

Servicio de Neurología. 'Servicio de Medicina Interna. Hospital de la Merced. Osuna, Sevilla. ${ }^{2}$ Unidad de Enfermedades Infecciosas. Hospital Universitario de Valme. Sevilla

1. Adams R, Victor M, Ropper AH. Anomalías de los movimientos y la postura a causa de enfermedad de los ganglios basales. En: Principios de Neurología. México. Ed. McGraw-Hill Interamericana Editores, S.A., 1999; 58-76.

2. Van Harten P N, Hoek HW, Kahn RS. Clinical review. Acute dystonia induced by drug treatment. BMJ. 1999; 319: 623-626.

3. Krogstad DJ, Herwaldt BL, Schesingler PH. Antimalarial agents: Specific treatment regimens. Antimicrob Agents Chemother. 1988; 32: 957-961. 
4. Jernigan JA, Pearson RD. Agentes antiparasitarios. En: Mandell GL, Bennet JE, Dolin R, eds. Enfermedades Infecciosas. Principios y practica. Buenos Aires. Editorial Medica Panamericana S.A. 1997; 508-544.

5. Phillips-Howard PA, ter Kuile FO. CNS adverse events associated with antimalarial agents. Fact or fiction?. Drug Saf 1995; 12: 370-83.

6. Man-Son-Hing M, Wells G, Lau A. Quinine for nocturnal leg cramps: a meta-analysis including unpublished data. J Gen Intern Med 1998; 13 (9): 600-606.

7. Achumba JI, Ette EI, Thomas WO, Essien EE. Chloroquine-induced acute dystonic reactions in the presence of metronidazole. Drug Intell Clin Pharm 1988; 22: 308-10.

8. Salako L A. Toxicity and side-effects of antimalarials in Africa: a critical review. Bull World Health Organ 1984; 62: 63-68.

\section{Enfermedad de Castleman localizada en región cervical}

\section{Sr. Director:}

La enfermedad de Castleman (EC), descrita por primera vez en 1956 (1), es un proceso linfoproliferativo poco frecuente que se caracteriza por hiperplasia de los ganglios linfáticos. Existen dos variedades histológicas (2) bien diferenciadas, la hialino-vascular y la plasmo-celular, que a su vez, pueden ser localizadas o multicéntricas. La forma hialino-vascular suele ser asintomática y localizada en mediastino, mientras que la plasmo-celular se presenta frecuentemente con sintomatología sistémica y suele ser difusa o multicéntrica. Presentamos un caso de enfermedad de Castleman tipo hialino- vascular a nivel cervical que consideramos de interés por lo poco frecuente de esta localización y sus implicaciones diagnósticas.

Mujer de 27 años, sin antecedentes patológicos de interés, que consultó por nódulo cervical de tres meses de evolución sin otros síntomas. A la exploración destacaba un tumor laterocervical derecho de $3 \mathrm{~cm}$ de diámetro, blando, móvil y no doloroso. El resto de la exploración era normal. Los exámenes de laboratorio, hemograma, VSG, proteinograma, función renal y hepática fueron normales. Las serologías para virus de hepatitis B y C, Ebstein-Barr, citomegalovirus, toxoplasma y virus de la inmunodeficiencia humana resultaron negativas. El factor reumatoide y los anticuerpos antinucleares fueron negativos. El Mantoux era negativo. La radiografía de tórax y la tomografía computarizada (TC) toraco-abdominal resultaron normales. La TC cervical informó de una única tumoración bien delimitada latero-cervical derecha que captaba contraste. Se realizó punción aspiración con aguja fina (PAAF) resultando negativos los cultivos de bacterias y micobacterias. Ante la falta de diagnóstico se decidió exéresis del nódulo. Se resecó un nódulo de $3 \times 2 \mathrm{~cm}$. El estudio microscópico anatomopatológico reveló una alteración ganglionar hiperplásica con una arquitectura general conservada y presencia de abundantes folículos cuyos centros germinales era poco prominentes, estos presentaban una marcada hiperplasia concéntrica de los linfocitos de la zona del manto junto con una proliferación vascular del tipo vénula y una hialinización de la pared, compatible con EC en su forma hialino-vascular.

La EC es una entidad rara, de etiopatogenia desconocida, que cursa con un aumento de la producción de interleucina 6 (IL 6) por parte de los nódulos hiperplásicos (3). La localización más frecuente es la mediasínica y la abdominal siendo rara la afectación cervical (10\%) (4). La forma histológica más frecuente de la EC es la hialino-vascular que afecta a individuos jóvenes, no existen diferencias en cuanto al sexo, y suele manifestarse como una adenopatía única bien delimitada asintomática o con escasa afectación sistémica (astenia, febrícula). Es una enfermedad benigna y curable mediante exéresis quirúrgica del ganglio. La variedad plasmo-celular, por el contrario, se suele presentar en la edad adulta, y clínicamente se caracteriza por fiebre, disminución de peso, astenia, linfadenopatías generalizadas, hepatoesplenomegalia, lesiones cutáneas y neuropatía. En los estudios de laboratorio destaca una elevación de la velocidad de sedimentación, hipergammaglobulinemia y anemia de trastornos crónicos. Las manifestaciones sistémicas se han asociado a un aumento de producción de IL 6 por las células plasmocelulares. El curso es agresivo y a menudo fatal, con una media de supervivencia de 30 meses (5), generalmente debido al desarrollo de complicaciones infecciosas y neoplasias, particularmente sarcoma de Kaposi o linfoma $(6,7)$.

Las técnicas de imagen como la TC o la resonancia magnética nuclear nos ayudan al diagnóstico informándonos de la localización, número y tamaño de las adenopatías afectadas, sobretodo teniendo en cuenta que la localización más frecuente es a nivel de mediastino. Pero el diagnóstico definitivo lo obtendremos mediante la biopsia del ganglio. En nuestro caso también fue preciso la exéresis quirúrgica para llegar al diagnóstico, descubriendo que nos hallábamos ante una EC tipo hialino-vascular en una región relativamente rara $(3,8)$. En esta variedad la extirpación del ganglio es diagnóstica, además de curativa, ya que todos los síntomas y alteraciones de laboratorio desaparecen tras la exéresis del tumor. Por el contrario, la forma plasmo-celular frecuentemente recidiva y degenera en una forma multicéntrica, falleciendo el enfermo en pocos meses. La extirpación quirúrgica es el tratamiento de elección en la forma localizada, habiendo poca información sobre el tratamiento de la forma multicéntrica. En esta última la evaluación de los diversos regímenes de tratamiento es complicado por el curso variable de la enfermedad, que incluye la remisión espontanea, y por el pequeño número de pacientes incluidos en los trabajos (5). El manejo de la EC después de la cirugía no está bien definido; en general, se aconseja un seguimiento a largo plazo, al menos durante 10 años. Los controles posteriores que realizamos a nuestra paciente mediante $\mathrm{TC}$ resultaron negativos, permaneciendo asintomática dos años después del diagnóstico.

En conclusión, queremos destacar que la EC de tipo hialinovascular puede presentarse como una masa cervical imitando otras etiologías más frecuentes como la tuberculosis y la neoplasia de las que debe diferenciarse. El diagnóstico definitivo y la curación se realizaran solo mediante la exéresis quirúrgica.

\section{A. López, I. Gázquez, A. Martín, M. Rubio}

Servicio de Medicina Interna. Hospital Universitario Arnau de Vilanova. Lleida

1. Castleman B, Iverson L, Pardo Menendes V. Localized mediastinal lymph node hyperplasia resembling Thymoma. Cancer 1956; 9: 822-830.

2. Keller AR, Hocholzer L, Castleman B. Hyaline-vascular and plasma-cell types of giant lymph node hyperplasia of the mediastinum and other locations. Cancer 1972; 29: 670-683.

3. Cuguillière A, Lonfon T, Ortega O. Une opacité mediastinale bénigne. Pneumol Clin 1997; 53: 21-26.

4. Serrablo Requejo A, del Agua Arias C, Iturbe Hernández T. Influencia del diagnóstico histopatológico en la expresividad clínica de la enfermedad de Castleman localizada: a propósito de dos casos. Rev Clin Esp 2000; 1: 26-28. 
5. Herrada J, Cabanillas F, Rice L. The clinical Behavior of Localized and Multicentric Castleman Disease. Ann Intern Med 1998; 128: 657-662.

6. Halkic N, Cornu P, Musimann F. Maladie de Castleman: deux observations inhabituelles. Schweiz Med Wochenschr 1998; 128: 9.

7. Sanz García RM, Guerra Vales JM, De Prada I, Martínez MA, Guillén Camargo V. Enfermedad de Castleman localizada asociada a linfoma de alto grado. An Med Interna (Madrid) 1999; 16: 305-307.

8. Coca Prieto I, Ortega Jiménez MV, Fernández Ruiz E, Gavilán Carrasco JC, Bermúdez Recio F. Enfermedad de Castleman localizada: descripción de un caso y revisión de la literatura. An Med Interna (Madrid) 2003; 20: 534-536.

\section{Un nuevo caso de gastroenteritis eosinofílica}

\section{Sr. Director:}

La gastroenteritis eosinofílica es una rara enfermedad de la que hasta el año 2000 había recogidos alrededor de 300 casos de los cuales 24 correspondian a España (1-4).

Esta enfermedad suele presentar eosinofilia periférica en un $80 \%$ aunque este no es un criterio diagnóstico. Los criterios diagnósticos son cuatro: presencia de síntomas gastrointestinales, infiltración eosinófila demostrada por biopsia de una o más áreas del tracto digestivo (más de 60 eosinófilos por campo de 10 aumentos), ausencia de infiltración eosinófila extraintestinal y ausencia de infección parasitaria (1).

La etiopatogenia es desconocida y se han postulados varias teorías siendo la más importante la que implica mecanismos alérgicos de hipersensibilidad inmediata tipo I con alergenos alimentarios $(1,5)$, aunque ésta por si sola no acaba de explicar del todo la etiología de la enfermedad. El mecanismo por el cual la eosinofilia se limita al tracto digestivo es desconocido pero parece ser que existen mecanismos locales que influyen en que los eosinófilos se acumulen y activen, implicándose en esto a tres citoquinas: interleukina 3 (IL3), el factor estimulador de granulocitos y macrófagos (GM-CSF) y la interleukina 5 (IL5) (6).

Las manifestaciones clínicas dependen de la capa de la pared preferentemente afectada. Si afecta a mucosa y submucosa (57,5\% de los casos) la clínica predominante es el dolor abdominal, náuseas, vómitos y diarreas principalmente. Si la capa más afectada es la muscular (30\% de los casos) la clínica principal obstrucción pilórica o suboclusión. Y si la capa más afectada es la serosa $(12,5 \%$ de los casos) la ascitis eosinofílica es la clínica más frecuente $(1,6)$.

Para el tratamiento se han estandarizado los glucocorticoides, buena respuesta, llegándose a utilizar azatioprina, ciclosporina $o$ azatioprina en casos resistentes a este tratamiento $(1,6)$.

Presentamos un nuevo caso recogido en nuestro servicio de Medicina Interna recientemente.

Paciente varón de 49 años con antecedentes de HTA en tratamiento médico que como dato epidemiológico presenta vivienda en ámbito rural y tiene contacto con gatos y perros. El paciente es remitido a nuestro servicio por su médico de cabecera para estudio de eosinofilia en sangre periférica. En la anamnesis los datos son negativos salvo molestias epigástricas que el paciente achaca al consumo de antinflamatorios por lumbalgia. La exploración física es normal y los estudios complementarios son los los siguientes: hemograma: serie roja y plaquetas normal, leucocitos $26700 / \mathrm{mm}^{3}$ (N: 19,3\%, L: 9,4\%, M: 4,8\%, E: 66,1\%, B: 0.4\%). VSG:5. Bioquímica: AST: 46,
ALT:74 resto normal (serologias de parásitos negativa, IgE normal). Coprocultivo y parásitos en heces negativo, aspirado de médula osea sin datos de neoplasia hematológica. La radiografía de tórax fue normal. Gastroscopia: signos de gastritis crónica con dos pequeñas lesiones prepilóricas; biopsia compatible con gastroenteritis eosinofílica.

Tras tratamiento con glucocorticoides el paciente presenta remisión del cuadro.

El caso nos parece interesante en primer lugar por lo insidioso de la clínica (molestias epigástricas) que el paciente achaca al consumo de AINE. Otro dato que se sale de lo habitual es el alto número de eosinófilos en sangre periférica $\left(17.640 / \mathrm{mm}^{3}\right)$ ya que generalmente suelen rondar entre los 1.000 y los 8.000 por $\mathrm{mm}^{3}$ (1). Este dato nos plantea entre los posibles diagnósticos diferenciales el descartar un síndrome eosinofílico idiopático, enfermedad que afecta a múltiples órganos y que tiene importantes implicaciones en el pronóstico y respuesta a tratamiento. Existe un dato característico que apoya el diagnostico de gastroenteritis eosinofílica, aparte del echo de no afectación de varios órganos, y es la presencia de una VSG normal (6), típico en esta enfermedad.

Cada vez existen más artículos con casos nuevos de esta enfermedad, con descripción de nuevas clínicas como son la ulcera duodenal (7), reflujo gastroesofágico (8) o la obstrucción biliar (9) y donde nos parece interesante incluir nuestro caso de molestias epigástricas. También se han planteado nuevos diagnósticos diferenciales pareciéndonos importante descartar mediante métodos serológicos la infección por el parásito Anisakis (10), aparte de los métodos habituales usados para descartar infecciones por otros parásitos.

\section{J. Oteiza, J. I. Berasategui, G. Tiberio, R. Campos}

Servicio de Medicina Interna. Hospital Virgen del Camino. Universidad Pública de Navarra. Ciencias de la Salud. Pamplona

1. Rodríguez Leal C, Tinoco Racero I, Téllez Pérez F, Girón González JA Gastroenteritis eosinofílica. Medicine 2000; 8: 238-241.

2. Remacha Tomey B. Palu A. Colom J. Ripollés V. Gastroenteritis eosinófilica. An Med Interna (Madrid) 1998; 15: 554-559.

3. Martínez Albaladejo M, Alguacil García G, González Pina B, De Paco Moya M, Herranz Marín T, Moreno-Requena J. Gastroneterirtis eosinofílica, a propósito de un nuevo caso. An Med Interna (Madrid) 1997; 14 : 187-189

4. De la Serna Higuera C, Rodriguez Gómez SJ, Martín Arribas MI, Martínez Moreno J, Pérez Villoria A. Gastroneteritis eosinófilica. Espectro clínico de una misma entidad. An Med Interna (Madrid) 2002; 19: 361364.

5. Greenberger N, Griboski JD. Allergic disorder of the intestine and eosinophilic gastroenteritis. En Gastrointestinal disease. Patophisiology, diagnosis management, de MH Sleisseger y JS Fordtran 1228. WB Saunders, Filadelfia 1978.

6. Remacha Tomey B, Palau A, Colom J, Ripollés V. Gastroenteritits eosinofílica. An Med Interna (Madrid) 1998; 15: 554-559.

7. Markowitz JE, Russo P, Liacouras CA. Solitary duodenal ulcer: a new presentation of eosinophilic gastroenteritis. Gastrointest Endosc 2000; 52: 673-6.

8. Liacouras CA, Markowitz JE. Eosinophilic esophagitis: a subset of eosinophilic gastroenteritis. Corr Gastroenterol Rep 1999; 1: 253-8.

9. Schoonbroodt D, Horsmans Y, Laka A, Geubel AP, Hoang P. Eosinophilic gastroenteritis presenting with colitis and cholangitis. Dig Dis Sci 1995: 40: 308-314.

10. Gómez B, Tabar AI, Tunon T, Larrinaga B, Álvarez MJ, García BE, Olaguibel JM. Eosinophilic gastroenteritis and Anisakis. Allergy 1998; 53: $1148-54$. 


\section{Disección espontánea de arterias carótidas. Presentación de un caso}

\section{Sr. Director:}

Los accidentes cerebro-vasculares agudos son entidades frecuentes en los servicios de urgencias. Entre sus causas destaca sobre todo la enfermedad aterotrombótica, pero existen otras menos frecuentes y quizás poco conocidas, entre ellas tenemos la disección espontánea de las arterias carótidas. Esta etiología supone un $2 \%$ de todos los ataques isquémicos pero en personas jóvenes y de mediana edad puede llegar a representar hasta un $10-25 \%$ de todos los ataques isquémicos.

Presentamos el caso de un varón de 67 años, fumador de 2-3 paquetes de cigarrillos al día y bebedor de más de $200 \mathrm{~g}$ de etanol al día.

El paciente acudió al servicio de urgencias hospitalario por presentar disminución de fuerza en hemicuerpo izquierdo y disartria. Presentó tres episodios en 24 horas que consistían en disminución de fuerza en miembro inferior izquierdo y desviación de la comisura bucal a la derecha, con recuperación espontánea en 10-15 minutos.

A la exploración el paciente se mostraba vigil y orientado con regular estado general, eupneico, sudoroso, con una frecuencia cardíaca de 50 ppm y una tensión arterial de 170/100 mmHg. La auscultación respiratoria revelaba roncus y sibilancias diseminadas por ambos campos pulmonares. Desde el punto de vista neurológico nos encontramos con un paciente perfectamente orientado, con temblor fino en manos, leve paresia facial izquierda pero con miembro superior izquierdo y miembro inferior izquierdo con fuerza y sensibilidad conservada. Tenía una leve ptosis en ojo derecho y diplopia en la mirada conjugada a la derecha.

En la evolución posterior se estableció una leve paresia de predominio crural en miembro inferior izquierdo.

El estudio hematológico, bioquímico y de coagulación fue normal. RPR negativo. Anticuerpos anti-nucleares negativos. Cuantificación de inmunoglobulinas: IgG 881, IgA 132 e IgM 54. Gasometría con leve hipoxemia $\left(\mathrm{pO}_{2} 76\right)$. Placa de tórax con signos de EPOC. ECG en ritmo sinusal a $50 \mathrm{lpm}$.

El TAC de cráneo realizado de urgencias no reveló imágenes de lesiones hemorrágicas.

Eco-doppler de cuello en el que se aprecia la presencia de ateromas calcificados laminares en ambas carótidas comunes. Se detecta mínimo flujo arterial en el inicio de la arteria carótida interna derecha por probable obstrucción por encima del área visible. Flujo potente en la arteria carótida interna contralateral compensador. Arterias carótidas externas normales.

Se realizó estudio angiográfico de troncos supraaórticos donde no se visualiza la arteria vertebral izquierda. Arteria vertebral derecha permeable. En la bifurcación carotídea derecha se apreciaba una obstrucción de la arteria carótida interna con extremo distal afilado dando lugar a una típica imagen en "llama" (Fig. 1). Carótida externa de calibre normal. Bifurcación carotídea izquierda con pequeñas irregularidades de la pared en relación con placas de ateroma.

El paciente fue tratado con heparina sódica intravenosa durante tres días seguido de HBPM. El tratamiento anticoagulante tuvo que ser suspendido por indicación del servicio de hematología debido a intolerancia, estando actualmente en tratamiento antiagregante. Su evolución posterior fue favorable estando después de 6 meses asintomático.

La disección arterial es causa de un $20 \%$ de ataques ocurridos en adultos por debajo de 40 años (1), es por tanto una causa importante de isquemia en la que se han involucrados una serie de factores patológicos como son la movilidad del cuello y el potencial lesivo de sus estructuras óseas, comenzando todo el proceso por un desgarro de la íntima.

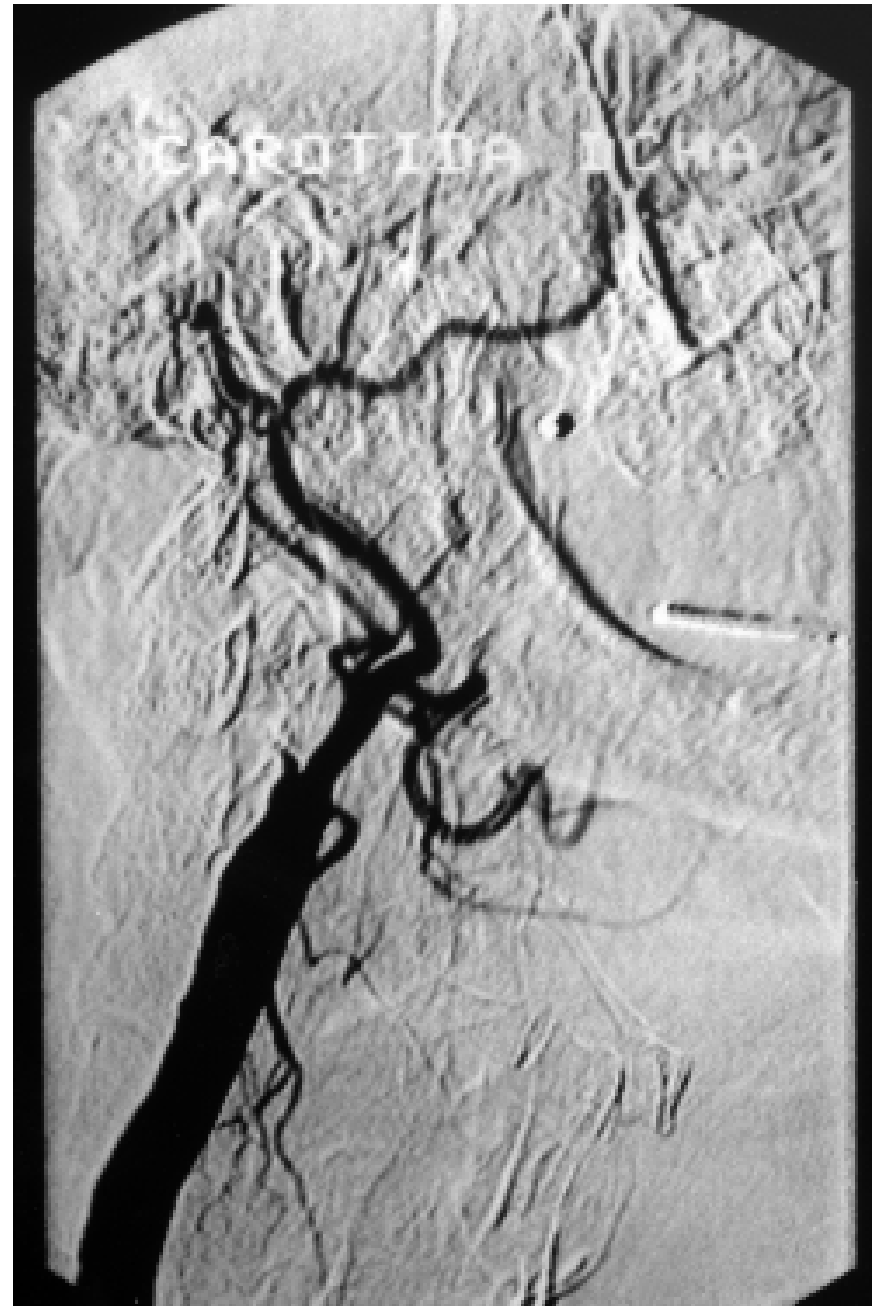

Fig. 1. Angiografía de carótida derecha. Vista lateral en la que se aprecia una obstrucción a nivel de la salida de la arteria carótida interna con una imagen en "Ilama" típica de disección.

En la patogénesis de este proceso se han implicado tanto factores genéticos como ambientales. Existen múltiples factores ambientales implicados, la mayoría relacionados con mecanismos de hiperextensión y rotación del cuello (yoga, pintar el techo, toser, vomitar, estornudar, recepción de anestesia, maniobras de resucitación, manipulación quiropráctica del cuello, historia reciente de infección respiratoria y migraña) (2). En cuanto a los genéticos destacan los defectos estructurales de la pared arterial en relación con enfermedades hereditarias del tejido conectivo (síndrome de Ehlers-Danlos tipo IV, síndrome de Marfan, enfermedad poliquística renal (AD) y osteogénesis imperfecta tipo I).

También se ha relacionado con la displasia fibromuscular, con la necrosis quística de la media así como con anomalías ultraestructurales del tejido conectivo dermal (3).

Los signos de disección carotídea suelen ser dolor sobre un lado (cabeza, cara o cuello) (4) acompañado de un síndrome de Horner parcial y seguido horas o días después por isquemia cerebral o retiniana. Esta triada se da en menos de un tercio de los pacientes aunque la presencia de sólo dos elementos de esta triada es muy sugestivo de disección. Este fue el caso de nuestro paciente que presentaba un síndrome de Horner parcial e isquemia cerebral de las que se recuperó totalmente. 
Las disecciones con alto grado de estenosis es más probable que produzcan obstrucciones intracraneales o eventos isquémicos retinianos mientras que disecciones sin estrechez causan más signos y síntomas locales (5).

Se ha propuesto incluir a la disección carotídea espontánea en el diagnóstico diferencial de la oclusión de la arteria central de la retina (6).

El diagnóstico de la disección espontánea ha experimentado un gran desarrollo gracias al avance de las técnicas de imagen. Para el manejo inicial se emplea sobre todo las técnicas de ultrasonografía (7), para el diagnóstico definitivo la angiorresonancia magnética ha desbancado a la angiografía convencional y se perfila como el patrón oro. El TAC Helicoidal es una técnica de futuro pero con una experiencia limitada en la actualidad (8).

La evolución de esta entidad suele ser buena aunque la mortalidad ronda el 5\%. Las estenosis se resuelven en el $90 \%$.

El manejo inicial suele ser médico reservando el quirúrgico y la angioplastia para casos muy seleccionados. El tratamiento de elección se basa en la anticoagulación (9), se inicia con heparina no fraccionada intravenosa seguido de anticoagulantes orales hasta normalizar el flujo sanguíneo o hasta un año después de la oclusión del vaso $(10,11)$.

Como puede verse la disección espontánea de arterias carótidas es una entidad cada día más frecuente y en la que hay que pensar ante cualquier déficit neurológico, sobre todo en pacientes jóvenes y de mediana edad, ya que puede confundirse fácilmente con un AIT o un ictus isquémico con los que habría que hacer el diagnóstico diferencial.

\section{Escobar Fernández, P. Morales Blanco, A. Ortiz Cansa- do}

\section{Servicio de Medicina Interna. Hospital Provincial. Badajoz}

1. Pérez Errazquin F, Gil Peralta A, Fernández García A, González Marcos JR, Muñoz A, Gil Neciaga E. Rev Neurol 1999; 28: 384-7.

2. Schievink WI. Spontaneous dissection of the carotid and vertebral arteries. N Engl J Med 2001. 344: 898-906.

3. Brant T, Orberk E, Weber R, Werner I, Bussed O, Muller BT, Wigger F, et al. Pathogenesis of cervical artery dissections: association with connective tissue abnormalities. Neurology 2001; 10, 57: 24-30.

4. Silbert PL, Mokri B, Schievink WI. Headache and neck pain in espontaneous internal carotid and vertebral artery dissections. Neurology 1995; 45: 1517-22.

5. Baumgartner RW, Arnold M, Baumgartner I, Mosso M, Gonner F, Stu$\operatorname{der}$ A, Schroth G, et al. Carotid dissection with and without ischemic events: local symptoms and cerebral artery findings. Neurology 2001; 57: 827-32.

6. Lubin J, Capparella J, Vecchione M. Acute monocular blindness associated with spontaneous common carotid artery dissection. Ann Emerg Med 2001; 38: 332-5.

7. De Bray J-M, Lhoste P, Dubas F, Emile J, Saumer J-L. Ultrasonic features of extracranial carotid dissections: 47 cases studied by angiography. J Ultrasound Med 1994; 13: 659-64.

8. Leclerc X, Godefroy O, Salhi A, Lucas C, Leys D, Pruvo JP. Helical CT for the diagnosis of extracranial internal carotid artery dissection. Stroke 1996; 27: 461-6.

9. Campos J, Alende MR, Castiñeira JA, Gonzalez A. Disección espontánea de la arteria carótida interna. An Med Interna (Madrid) 2003; 20 56-57.

10. Brandt T, Caplan L. Spontaneous Arterial Dissection. Curr Treat Options Neurol 2001; 5: 463-469.

11. Schievink WI. The treatment of spontaneous carotid and vertebral artery dissections. Curr Opin Cardiol 2000; 15: 316-21.

\section{Corynebacterium macginleyi como agente excepcional de endocarditis infecciosa: a propósito de un caso}

\section{Sr. Director:}

Las bacterias pertenecientes al género Corynebacterium son bacilos gram positivos pleomórficos, aerobios o anaerobios facultativos, no móviles y no formadores de esporas (1). La especie $C$. macginleyi fue definida en 1995 por Riegel y cols. (2) durante investigaciones de corinebacterias lipofílicas. Dado que afecta predominantemente el tejido conjuntival todos los casos descritos como responsable patogénico están relacionados con patología conjuntival.

Dentro del género Corynebacterium hay múltiples especies habiendo sido descritas algunas de ellas como responsables de endocarditis Infecciosa (EI) como el $C$. diphtheria $(1,4), C$. Striatum (4,5) Corynebacterium CDC grupo A-4 (1), C. jeikeium (1), C. C. pilosum (1), Corynebacterium grupo D2 (1), Pseudodiphteriticum (1,4), C. minutissimum $(1,4), C$. bovis $(4,6), C$. haemolyticum $(4,6)$, C. pyogenes $(4,6)$.

Presentamos el primer caso descrito en la literatura de endocarditis por $C$. macginleyi.

Varón de 67 años, con antecedentes de enolismo moderado. Antecedentes patológicos de HTA, dislipemia, diabetes mellitus insulinodependiente de larga evolución con arteriopatía, neuropatía, retinopatía y nefropatía diabética; mal perforante plantar a nivel del primer metatarsiano del pie izquierdo y doble valvulopatía mitral leve. Diez días antes del ingreso actual, acudió a nuestro centro por cuadro de fiebre sin focalidad infecciosa. Dos hemocultivos fueron positivos a Corynebactrium spp que se interpretó como probable contaminación ante la ausencia de hallazgos clínicos y exploratorios. Fue tratado empíricamente con amoxicilina-clavulánico desapareciendo la fiebre. A los tres días del alta, reingresa por reaparición de fiebre y escalofríos. La exploración física no mostró cambios respecto al primer ingreso ni tampoco la radiografía de tórax, ni el urocultivo. La analítica mostró: leucocitos $8,61 \times 10 \mathrm{E}^{9} / \mathrm{L}$; formula leucocitaria: granulocitos $65,9 \%$, linfocitos $22,6 \%$, monocitos $8,8 \%$, eosinófilos $0,90 \%$, basófilos $0,20 \%$ hematíes 3,75 x 1,E12/L: hemoglobina 9,60 g/dl; hematocrito 30,30\%; VCM 80,60 fl; plaquetas $198 \times$ 10E9/L; HbA1C $8,1 \%$. Se realizaron cuatro hemocultivos que fueron positivos a Corynebaterium spp, posteriormente identificado como $C$. macginleyi por el sistema API CORYNE . El ecocardiograma transtorácico mostró una doble lesión mitral moderada de origen reumático con profusa calcificación de la valva anterior sin objetivarse imágenes de vegetaciones. El ecocardiograma transesofágico evidenció la presencia de una vegetación filiforme en valva anterior mitral con insuficiencia mitral. Con la orientación diagnóstica de endocarditis mitral por $C$. macginleyi se inició tratamiento con ampicilina ev $(12 \mathrm{~g} / 24 \mathrm{~h})$ durante cuatro semanas y gentamicina durante los primeros quince días. El paciente evolucionó favorablemente durante su estancia en el hospital quedando afebril a partir de las primeras veinticuatro horas del inicio del tratamiento antibiótico, siendo dado de alta y estando asintomático y con hemocultivos negativos en controles realizados a los tres y seis meses.

Las corinebacterias no diftéricas son infrecuentes pero se reconocen como agentes etiológicos de EI. Los factores de riesgo que predisponen a la EI por corinebaterias son la inmunodepresión, ser portador de catéter venoso central, haber padecido una endocarditis previa, ser portador de prótesis valvulares o en válvulas previamente dañadas $(1,3)$, siendo menos frecuente por corinebacterias la endocarditis sobre válvula nativa (3). Las válvulas afectadas con más frecuencia son la válvula mitral y aórtica. 
La sensibilidad del género Corynebacterium es muy variable y algunas especies pueden ser resistentes a gran cantidad de antibióticos, por lo que es recomendable realizar siempre estudios de sensibilidad antimicrobiana cuando se considera la posibilidad de que sean responsables de una patología determinada. Sin embargo dado que es bastante frecuente que sean sensibles a la penicilina, muchas EI producidas por estos microorganismos se tratan con penicilina sola o en combinación con gentamicina por si ambos antibióticos pudieran tener efecto sinérgico (1).

El C. macginleyi hasta la actualidad únicamente se ha aislado en tejidos oculares considerándose un patógeno que afecta predominantemente la conjuntiva ocular dañada. Dado que es altamente sensible a casi todos los antibióticos tópicos probablemente los tratamientos administrados empíricamente consiguen erradicar el microorganismo con facilidad y por tanto ser la prevalencia de dicho germen como patógeno ocular superior a la descrita en la literatura.

Describimos el primer caso de EI por C. macginleyi y por tanto el descrito de afectación extraocular por dicho germen. Se trata de una endocarditis sobre la valva anterior de una válvula mitral reumática. El hecho de tratarse de un enfermo con diabetes severa como enfermedad de base y el ser portador de una válvula mitral reumática probablemente predispuso a la afectación por dicho microorganismo. La evolución clínica favorable del paciente con ampicilina y gentamicina corrobora que frecuentemente la sensibilidad de los Corynebacterium a la penicilina es alta como se ha descrito anteriormente en la literatura. En nuestro caso el germen presentó sensibilidad a penicilina, ampicilina, ceftriaxona, vancomicina y gentamicina y resistencia a eritromicina, clindamicina, cotrimoxazol y ciprofloxacino.

Dado que cada vez hay mayores posibilidades de identificación en los laboratorios, quizás en el futuro se aísle con más frecuencia $C$. macginleyi, pudiéndose conocer su importancia como patógeno no solo a nivel ocular. Además, si bien a menudo las corinebaterias se consideran microorganismos contaminantes de los cultivos en general, su aislamiento repetido en hemocultivos debe valorarse en el contexto clínico del enfermo para detectar los casos en que puede tener valor como patógeno y de esta forma iniciar el tratamiento adecuado lo antes posible para evitar complicaciones.

\section{Pubill Sucarrat, X. Martínez-Costa, G. Sauca Subías, J. A. Capdevila Morell}

Servicio de Medicina Interna. Hospital de Mataró. Consorci Sanitari del Maresme. Barcelona

1. Prada JL, Villanueva JL, Torre-Cisneros J, Anguita M, Escauriaza J, Sánchez-Guilo P. Endocarditis por Corynebacterium no diphteriae. Presentación de 7 casos y revisión. Enferm Infecc Microbiol Clin 1993; 11: 536-42.

2. Riegel P, Ruimy R, De Briel D, Prevost G, Jehl F, Christen R, Monteil $\mathrm{H}$. Genomic duversity and phylogenetic relationships among lipidrequiring diphteroids from humans and characterization of Corynebacterium macginleyi sp. Int J Syst Bacteriol 1995; 45: 128-133

3. Tiley SM, Kociuba KR, Heron LG, Munro R. Infective endocarditis due to nontoxigenic Corynebacterium diphteriae: report of seven cases and review. Clin Infect Dis 1993; 16: 271-275

4. Rufael DW, Cohn SE. Native valve endocarditis due to Corynebacterium striatum: case report and review. Clin Infect Dis 1994; 19: 1054-61.

5. Juurlink DN, Borczyk A, Simor AE. Native valve endocarditis due to Corynebacterium striatum. Enz J Clin Microbiol Infect Dis 1996; 15: 963-5.
6. Gálvez MC, Díez F, González-Gay JM, López G, Collado A, Laynez F. Fiebre de larga evolución y exantema recidivante como manifestaciones de endocarditis por Corynebacterium sp Enferm Infecc Mibrobiol Clin 1994; 12: 414-415.

7. Losada JM. Daza RM, Mendoza MP, Martínez C, Azofra J, Merino J et al. Corynebacterium G1. Enferm Infecc Microbiol Clin 1994; 12: 362

8. Ortiz de la Tabla V, Martín C, Martínez C. Conjuntivitis por Corynebacterum macginleyi. Enferm Infecc Microbiol Clin 2000; 18: 481-482.

9. Joussen AM, Funke G, Joussen F, Herbertz G. Corynebacterium macginleyi: a conjunctiva specific pathogen. Br J Ophtalmol 2000; 84: 1420-22.

10. Funke G, Pagano-Niederer N, Bernauer W. Corynebacterium macginleyi has to date been isolated exclusively from conjunctival swabs. J Clin Microbiol 1998; 36: 3670-3673.

Divertículo duodenal periampular: una entidad a considerar en el diagnóstico diferencial del absceso pancreático

\section{Sr. Director:}

El divertículo duodenal periampular (DDP) es un proceso patológico relativamente frecuente que puede plantear dificultades diagnósticas de consideración si no es tenido en cuenta a la hora de valorar colecciones pancreáticas, en especial, las que tienen gas. Se presenta el caso de una paciente con una pancreatitis aguda biliar en el que existía una colección pancreática sugestiva de absceso y que resultó corresponder a un DDP.

Se trata de una mujer de 74 años con antecedentes de hipertensión arterial, talasemia minor y artritis reumatoide que consultó por dolor epigástrico irradiado a ambos hipocondrios y vómitos biliosos de 6 horas de evolución. La palpación abdominal era dolorosa sobre todo en hipocondrio derecho aunque no existía signo de Murphy ni irritación peritoneal. En la analítica destacó: leucocitos 24.510/mm3 con predominio de neutrófilos, hemoglobina 10,6 g/l, VCM 66, pla-

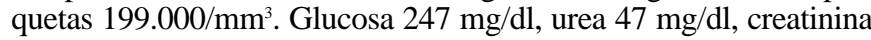
$0,6 \mathrm{mg} / \mathrm{dl}$, bilirrubina total $1,4 \mathrm{mg} / \mathrm{dl}$, GOT $96 \mathrm{U} / \mathrm{l}$, GPT $219 \mathrm{U} / \mathrm{l}$, GGT $118 \mathrm{U} / \mathrm{l}$, fosfatasa alcalina $252 \mathrm{U} / \mathrm{l}$, LDH $146 \mathrm{U} / \mathrm{l}$, amilasa $4.104 \mathrm{U} / \mathrm{l}$, lipasa $278 \mathrm{U} / \mathrm{l}$, calcio $9,2 \mathrm{mg} / \mathrm{dl}$, proteínas totales 9,6 $\mathrm{mg} / \mathrm{dl}$ (albúmina $4,4 \mathrm{mg} / \mathrm{dl}$ ). VSG $24 \mathrm{~mm} / \mathrm{h}$, PCR a las 48 horas: $0,87 \mathrm{mg} / \mathrm{l}(\mathrm{VN}<1)$. Gasometría arterial basal: $\mathrm{pH} 7,38, \mathrm{pO} 266$ $\mathrm{mmHg}$, pCO2 $38 \mathrm{mmHg}, \mathrm{HCO} 326$. La radiografía de tórax fue normal y la ecografía abdominal mostró un páncreas edematoso y múltiples cálculos en la vesícula biliar. Con el diagnóstico de pancreatitis aguda biliar se inició dieta absoluta, reposición hidroelectrolítica y tratamiento analgésico. Solicitamos una tomografía computarizada (TC) abdominal con contraste oral y endovenoso que evidenció en la zona de la cabeza de páncreas una colección con nivel hidroaéreo de $2 \mathrm{~cm}$ y de bordes bien definidos. Ante los hallazgos del TC abdominal se realizó un tránsito gastroduodenal que mostró una imagen diverticular de $3 \times 2 \mathrm{~cm}$ con relleno parcial de material de contraste localizada en el tercio medio de la segunda porción del duodeno (borde pancreático) (Fig. 1). La duodenoscopia con visión lateral confirmó la presencia de una papila de Vater intradiverticular.

La incidencia de divertículos de duodeno en las series autópsicas varía entre el 6 y el $22 \%$ y son un hallazgo casual en hasta el 5\% de las exploraciones baritadas del tracto digestivo superior. Pueden llegar a tener un gran tamaño pero la mayoría miden entre 1 y 5 centímetros. Se trata de lesiones adquiridas formadas por una saculación de la mucosa y submucosa que se hernian a través de un defecto muscular (1). Con más frecuencia se localizan en el borde medial 


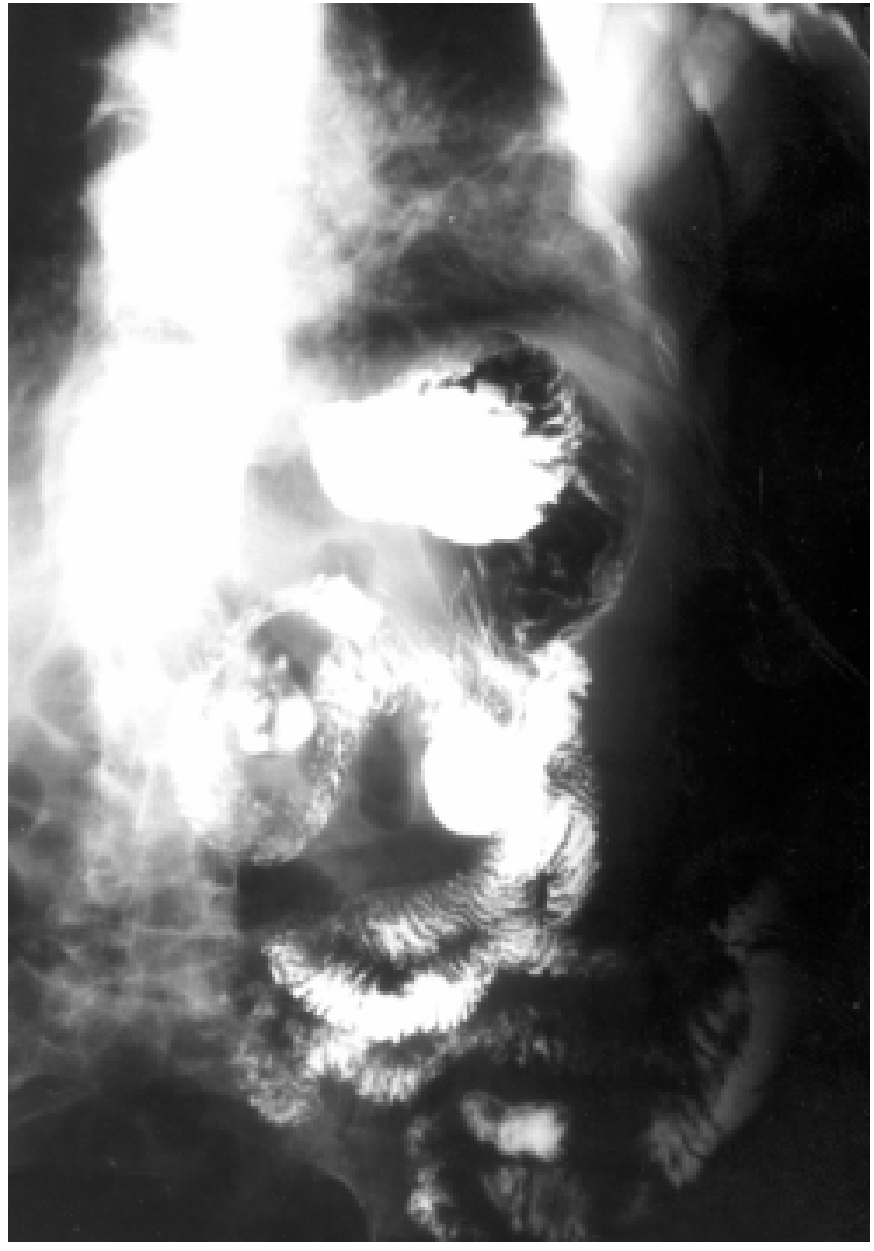

Fig. 1. Tránsito gastroduodenal. Divertículo en la segunda porción del duodeno.

del duodeno descendente y en la región periampular aunque también pueden verse en la tercera y cuarta porción duodenal e incluso en el borde lateral del duodeno descendente (2). Suelen ser asintomáticos pero pueden complicarse con hemorragias, perforación o formación de abscesos o fístulas. La diverticulitis aguda es rara y puede confundirse clínicamente con otros procesos abdominales como úlcera gastroduodenal, pancreatitis o colecistitis (3). Por otra parte, la relación entre el DDP y la presencia de enfermedad obstructiva biliar y pancreática está todavía por definir (4). El diagnóstico suele realizarse mediante un tránsito gastrointestinal en el que los divertículos duodenales, casi siempre múltiples y de morfología redonda, cambian de configuración mientras se está efectuando la exploración. Con la endoscopia convencional pueden pasar desapercibidos los DDP y los de menor tamaño por lo que es preferible la duodenoscopia con visión lateral $(1,3)$.

En relación con el caso presentado, queremos resaltar los problemas de diagnóstico diferencial que puede plantear el DDP con otras entidades cuyo tratamiento es muy diferente. El DDP puede alcanzar un gran tamaño y aparecer como una colección de gas que limita en su crecimiento medial por tejido pancreático y por lo tanto puede ser interpretado incorrectamente como un ciego dilatado, un absceso o pseudoquiste pancreático o hasta una neoplasia de cabeza de páncreas (5). La TC abdominal de nuestra paciente mostró una colección pancreática sugerente de absceso. Sin embargo, aunque la imagen radiológica de una colección pancreática bien definida y con gas puede llegar a ser muy indicativa de absceso, siempre debe tenerse en cuenta la situación clínica del enfermo que suele estar grave, a menudo con fiebre, leucocitosis, íleo paralítico o manifestaciones clínicas mantenidas de una pancreatitis grave. Además, el absceso pancreático suele aparecer en fases tardías de la pancreatitis, generalmente a partir de la segunda y tercera semana (6). En nuestra enferma, la satisfactoria evolución clínica y analítica de la pancreatitis no hacía pensar inicialmente en la posibilidad de un absceso pancreático. Por tal motivo, pensamos que la colección pancreática con gas podría corresponder a un DDP. El tránsito gastroduodenal demostró la presencia del divertículo en la segunda porción duodenal y la duodenoscopia con visión lateral mostró la papila de Vater intradiverticular.

Por tanto, creemos importante incluir en el diagnóstico diferencial de las colecciones pancreáticas bien definidas y que tienen gas al DDP. Si se sospecha su presencia, la demostración del mismo mediante un tránsito gastroduodenal o una duodenoscopia con visión lateral puede llegar a tener, como en nuestra enferma, importantes implicaciones diagnósticas y terapéuticas.

\section{F. López García, G. Belda Abad ${ }^{1}$, J. A. Correa Estañ ${ }^{1}$, R. Cruz Novoa, F. Boluda Belíjar ${ }^{2}$}

Servicio de Medicina Interna, ${ }^{1}$ Digestivo $y{ }^{2}$ Radiodiagnóstico. Hospital de Vega Baja. Orihuela, Alicante

1. Harford WV. Diverticula of the hypopharinx and esophagus, the stomach and the small bowel. En: Feldman M, Scharschmidt BE, Sleisenger MH, eds. Gastrointestinal and liver disease. $6^{\mathrm{a}}$ ed., Vol I. Filadelfia, WB Saunders company, 1998; 309-16.

2. Hwang JI, Chiang JH, Yu C, Cheng HC, Chang CY, Mueller PR. Pictorial review: Radiological diagnosis of duodenal abnormalities. Clin Radiol 1998; 53: 323-32.

3. Oddo F, Chevallier P, Souci J, Baque J, Buckley MJ, Fabiani P et al Radiologic aspects of the complications of duodenal diverticula. J Radiol 1999; 80: 134-40.

4. Zoepf T, Zoepf DS, Arnold JC, Benz C, Rienmann JF. The relationship between juxtapapillary duodenal diverticula and disorders of the biliopancreatic system: analysis of 350 patientes. Gastrointest Endosc 2001; 54: 56-61.

5. Wagner W, Ahlbrand P, Bottcher HD, Musswessels F. Duodenal diverticulum; possibility for erroneous diagnosis in the sonographic diagnosis of pancreas head tumor. Ultraschall Med 1985; 6: 46-8.

6. Bradley EL, Olsen RA. Current management of pancreatic abscess. Adv Surg 1991; 24: 361-88.

\section{Prolongación del intervalo QT en un paciente con enfermedad coronaria tratado con mianserina}

\section{Sr. Director:}

La prolongación del intervalo QT puede ser congénita y adquirida. La forma adquirida puede deberse a hipersensibilidad a fármacos $(1,2)$, alteraciones electrolíticas, lesiones del sistema nervioso central y bradiarritmias excesivas. También puede prolongarse en distintas patologías como la isquemia miocárdica o alteraciones hepáticas.

Entre los fármacos psicoactivos es conocido el potencial efecto cardiotóxico de los antidepresivos tricíclicos, que incluso en dosis bajas pueden prolongar el intervalo QT (3). Sin embargo, la mianserina -antidepresivo tetracíclico- demostró estar asociada con una baja tasa de efectos cardiovasculares adversos $(4,5)$.

Mujer de 77 años con cardiopatía isquémica e hipertensiva de varios años de evolución y asma bronquial intrínseco. Rea- 
lizaba tratamiento con verapamil (240 mg), nifedipina (30 mg), nitratos en parche $(15 \mathrm{mg})$, ácido acetilsalicílico $(100 \mathrm{mg})$, espironolactona $(25 \mathrm{mg})$, altizide $(15 \mathrm{mg})$ y beclometasona inhalador. Ingresa en nuestro centro por presentar tres crisis de angor pectoris, que aparecieron en reposo y que cedieron con nitratos.

La anamnesis reveló cuadro depresivo de dos meses de evolución. En la exploración destacaba un soplo mesosistólico eyectivo I/VI en ápex, con roncus y sibilantes en ambos campos pulmonares. La radiografía de tórax era normal. En el electrocardiograma de ingreso se observaba ritmo sinusal, intervalo PR $0,20 \mathrm{~s}$, intervalo QT corregido normal, bloqueo completo de rama derecha, hemibloqueo izquierdo anterior y alteraciones difusas de la repolarización con presencia de ondas $\mathrm{T}$ negativas desde V1 a V5.

El primer día de su ingreso se inició tratamiento con diltiazem (240 mg), nifedipina (30 mg), mononitrato de isosorbida (120 $\mathrm{mg}$ ), ácido acetilsalicílico $(100 \mathrm{mg})$, espironolactona $(25 \mathrm{mg})$, altizide $(15 \mathrm{mg})$ y beclometasona inhalada. En el segundo día de hospitalización se añadió $10 \mathrm{mg}$ /día de mianserina.

En el electrocardiograma practicado 10 horas después del tratamiento con mianserina se evidenció una prolongación marcada del intervalo QT corregido ( $0.60 \mathrm{~s})$ y las alteraciones de repolarización se hicieron más marcadas (Fig. 1). El hemograma, proteinograma y perfil bioquímico eran normales. El estudio ecocardiográfico fue normal. Tras retirar la mianserina el electrocardiograma fue similar al de ingreso, normalizándose el intervalo QT corregido. La paciente se mantuvo asintomática desde su ingreso sin volver a presentar crisis de angina.

La mianserina es un antidepresivo tetracíclico. Carece de la cadena lateral responsable de la actividad anticolinérgica de los antidepresivos tricíclicos. Bloquea receptores alfa presinápticos, es antagonista de receptores de serotonina y bloqueante

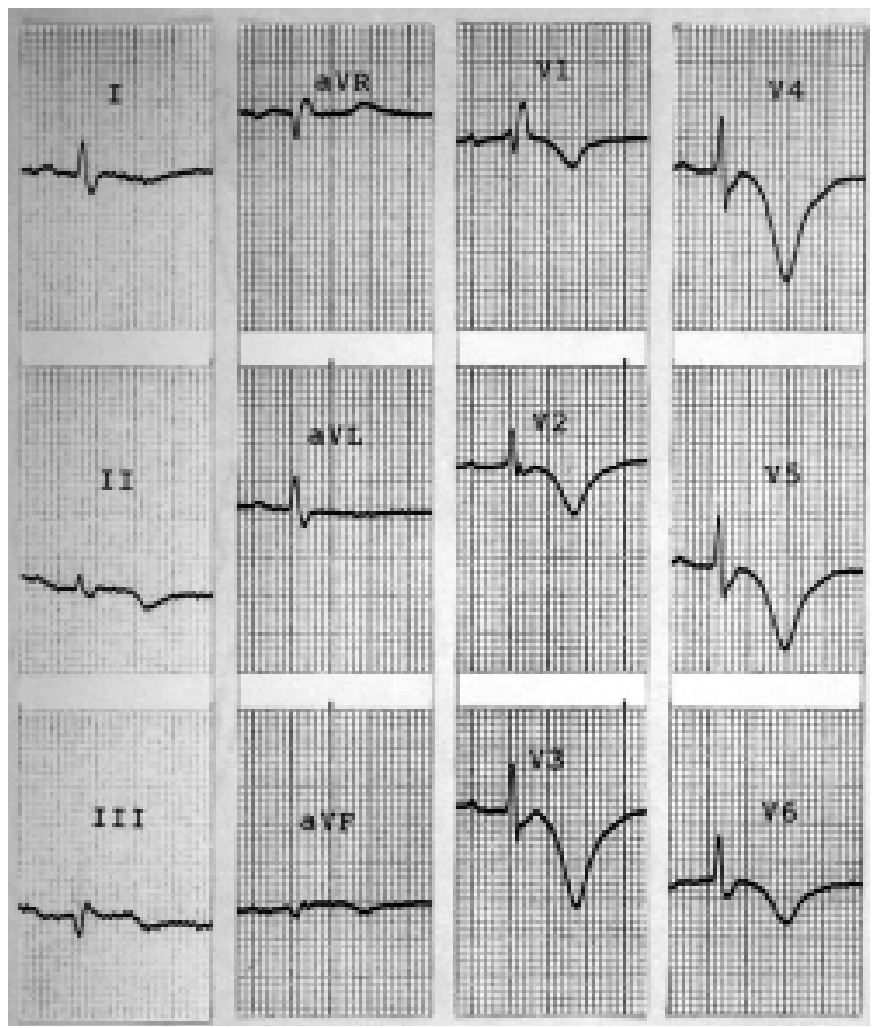

Fig. 1. A las 10 horas de la administración de una dosis de $10 \mathrm{mg}$ de mianserina se observó una prolongación marcada del intervalo QTC (0,60 seg) acentuándose las alteraciones de la repolarización. de los receptores H1 histamínicos. Su vida media plasmática es bifásica, con una duración de la fase terminal entre 6 y 40 horas.

La mianserina es muy usada en pacientes mayores y se considera que tiene escasos efectos adversos cardiovasculares $(3,4)$, aunque se han comunicado efectos adversos en pacientes individuales. Con mianserina a dosis terapeúticas se ha descrito hipotensión ortostática, hipertensión, deterioro de la función ventricular izquierda en pacientes mayores (6) y la aparición de bradicardia sintomática (7); efectos que desaparecieron al suspender el tratamiento. En pacientes con sobredosis de mianserina se ha reportado bloqueo auriculoventricular completo y fibrilación ventricular recurrente (8). Sin embargo, en la bibliografía no hemos encontrado trabajos que refieran prolongación del intervalo QT inducida por mianserina.

En nuestra paciente constatamos un alargamiento del intervalo QTc 10 horas después de haber administrado mianserina, lo que sugiere que este fármaco fue la causa más probable de prolongación del QTc, normalizándose el electrocardiograma tras suspender el tratamiento.

La aparición de este efecto, con una dosis (10 mg) inferior a la dosis de inicio más recomendada (30-40 mg/día), nos lleva a pensar que la prolongación del QTc en esta paciente podría depender de variables como la susceptibilidad individual, sexo (9), edad o genéticas y de la enfermedad cardiaca concomitante.

Las alteraciones de repolarización generalizadas presentes en la figura 1 pensamos que son secundarias al uso del fármaco ya que estas alteraciones tras el uso de fármacos antidepresivos está suficientemente descrita (10).

En nuestro caso, el tiempo transcurrido desde la última crisis de angina hasta la prolongación del QTc (40 horas), la ausencia de clínica durante su ingreso y el tener documentados electrocardiogramas anteriores con angor sin prolongaciones del QT nos hace pensar que la prolongación del intervalo QTc estuvo relacionada con el uso de mianserina, aunque la enfermedad coronaria constituyera una circunstancia agravante.

En conclusión, aunque los efectos cardiotóxicos de la mianserina son inferiores a los de los antidepresivos tricíclicos, debería usarse con precaución en pacientes con enfermedad arterial coronaria.

R. J. Hidalgo Urbano, E. Díaz Infante, A. Recio Mayoral, F. López Rincón' ${ }^{1}$, J. Gutiérrez de la Peña ${ }^{1}$, J. M. Cruz Fernández

Unidad Coronaria. Servicio de Cardiología. Hospital Universitario Virgen Macarena. Sevilla. ${ }^{1}$ Unidad de Cardiología. Hospital Punta de Europa. Algeciras, Cádiz.

1. Crouch MA, Limon L, Cassano AT. Clinical relevance and management of drug-related QT interval prolongation. Pharmacotherapy. 2003; 23: 881-908.

2. Fermini B, Fossa AA. The impact of drug-induced QT interval prolongation on drug discovery and development. Nat Rev Drug Discov. 2003; 2 (6): 439-47.

3. Johnson A, Giuffre RM, O'Malley K. ECG changes in pediatric patients on tricyclic antidepressants, desipramine, and imipramine. Can J Psychiat 1996; 41: 102-106.

4. Leionen E, Koponen H, Lepola U. Serum mianserin and ageing. Prog Neuropsychopharmacol Biol Psychiatry 1994; 18: 833-845.

5. Hourdebaigt-Larrusse $P$, Perchet $H$. Mianserin in acute cardiopathies 27 cases recorded in a medical intensive care unit. Ann Cardiol Angeiol 1985; 34: 637-641.

6. Moller M, Thayssen P, Kragh-Sorensen P, Pedersen OL, Kristensen CB, Bjerre M, Benjaminsen S, Gram LF: Mianserin: cardiovascular effects in elderly patients. Psychopharmacology 1983; 80 (2): 174-177. 
7. Carcone B, Vial T, Chaillet N, Descotes J. Symptomatic bradycardia caused by mianserin at therapeutic doses. Hum Exp Toxicol 1991; 10 (5): 383-384

8. Haefeli WE, Schoenenberger RA, Scholer A. Recurrent ventricular fibrillation in mianserin intoxication. Br Med J 1991; 302: 415-416.

9. Makkar RR, Fromm BS, Steinman RT, Meissner MD, Lehmann MH. Female gender as a risk factor for torsades de pointes associated with cardiovascular drugs. JAMA 1993; 270 (21): 2590-2597.

10. Fisch C. Electrocardiografía. En: Braunwald E, editor. Tratado de Cardiología $5^{\text {a }}$ edición. MacGraw Hill Interamericana, 1999; 150.

\section{Bacteriemia por Capnocytophaga y embolismos pulmonares}

\section{Sr. Director:}

Capnocytophaga spp es un bacilo gramnegativo, fusiforme, capnofílico, catalasa-negativo, oxidasa-negativo y anaerobio facultativo; de crecimiento lento y forma parte de la microflora orofaríngea (1). Existen cinco especies clasificadas en dos grupos con distintas características patogénicas y fenotípicas. El grupo DF-1 (fermentadores disgónicos-1) que incluye las especies $C$. gingivalis, $C$. ochracea y $C$. sputigena; se asocian a bacteriemias y endocarditis secundarias a lesiones de la cavidad oral (mucositis, gingivitis, periodontitis, etc.) en enfermos inmunodeprimidos. También se han descrito infecciones diseminadas en personas inmunocompetentes pero son excepcionales $(1,2)$. Un segundo grupo el DF-2 lo componen las especies C. canimorsus y C. cynodegmi; los cuales forman parte de la microflora oral de perros y gatos pudiendo producir bacteriemias y meningitis tras mordeduras o arañazos en pacientes inmunodeprimidos e inmunocompetentes (2-5). Se han descrito casos con mera exposición a animales (27\%) (5) como sucede en nuestro caso. La mayoría de casos descritos en la literatura se trata de casos clínicos aislados o series limitadas en número (3-8).

Presentamos por su infrecuencia el caso de un proceso neumónico en un paciente joven inmunocompetente que presentó una bacteriémia por Capnocytophaga spp con coagulación intravascular diseminada (CID) y embolismos pulmonares, sin factores predisponentes a excepción de ingesta etílica moderada y contacto con perros y gatos; teniendo una evolución favorable.

Se trata de un varón de 26 años sin antecedentes personales de interés, fumador de 40 cigarrillos/día y bebedor moderado; sin alergias conocidas ni otros hábitos tóxicos. Profesión transportista. No refiere en los meses previos mordeduras ni arañazos de animales, aunque tiene contacto con perros y gatos. No ha realizado viajes al extranjero.

Presentó dolor submamario izquierdo de 20 días de evolución con sudoración y tos productiva sin fiebre; junto con astenia, anorexia y pérdida de $12-15 \mathrm{~kg}$.

En la exploración física presenta; tensión arterial 115/60, frecuencia cardíaca $100 \mathrm{lpm}$, frecuencia respiratoria $20 \mathrm{rpm}$, temperatura $40,5^{\circ} \mathrm{C}$. Consciente, orientado, pálido y sudoroso. No injurgitación yugular. Faringe normal sin inflamación ni úlceras bucales. Adenopatías axilares bilaterales e inguinales. Taquicárdico con soplo sistólico I/IV y auscultación pulmonar normal. Hepatoesplenomegalia dolorosa.

En la analítica destacaba; hemoglobina $10 \mathrm{~g} / \mathrm{dl}$, hematocrito $29 \%$, leucocitos $25.000 / \mathrm{mm}^{3}$ (84 segmentados y 2 cayados) y plaquetas $73.000 / \mathrm{mm}^{3}$. T. Protrombina $67 \%$. Glucemia 135 $\mathrm{mg} / \mathrm{dl}$, Na $133 \mathrm{mEq} / \mathrm{l}, \mathrm{K} 3,5 \mathrm{mEq} / \mathrm{l}$, amilasa $125 \mathrm{U} / \mathrm{l}$, GOT 55

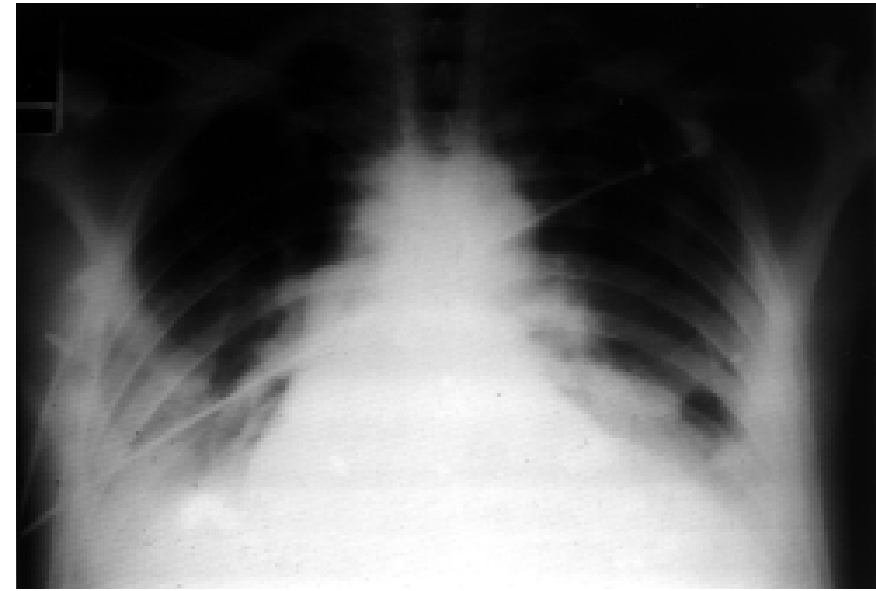

Fig. 1. Radiografía de tórax posteroanterior: Infiltrados pulmonares bilaterales cavitados.

U/l, GPT 100 U/l, gamma-GT 36 U/l, albumina 2,3 g/dl, proteínas totales 5,2 g/dl y VSG elevada. Rosa de Bengala negativo. Gasometría arterial pH 7,50, $\mathrm{pCO}_{2} 32, \mathrm{pO}_{2} 73, \mathrm{HCO}_{3}-25$. Serología virus hepatitis $\mathrm{C}$ positiva. Serología citomegalovirus y virus de Epstein Barr positiva a títulos bajos. VIH Negativo. ECG: taquicardia sinusal. En la radiografía de tórax presentó condensación en base izquierda con derrame pleural bilateral sin signos de insuficiencia cardíaca; siendo los resultados bioquímicos de la toracocentesis: $\mathrm{pH} 7,5$, proteinas 2,2 y glucosa 97. Ecografía y tomografía axial computarizada (TAC) abdominal: Hepatoesplenomegalia sin lesiones ocupantes de espacio. El paciente recibió tratamiento antibiótico con Eritromicina y Doxiciclina por supuesta neumonía en base izquierda; presentando de forma súbita un empeoramiento de su estado general desarrollando embolismos pulmonares y shock séptico con CID. Se le realizó nueva radiología de tórax postero-anterior y lateral (Fig. 1) con el resultado de infiltrados pulmonares bilaterales cavitados, sugerentes de infarto séptico y una TAC toracoabdominal donde se evidenció la presencia del derrame pleural y de varias lesiones cavitadas, una de ellas en base pulmonar derecha. Ante la sospecha de endocarditis, se indico un estudio ecocardiográfico con el resultado de insuficiencia tricuspídea leve con ligero derrame pericárdico sin hipertensión pulmonar ni verrugas. Se inició tratamiento antibiótico empírico con levofloxacino, clindamicina, vancomicina y amikacina. Los hemocultivos solicitados resultaron positivos para Capnocytophaga spp.

Evolucionó favorablemente, aunque presentó de nuevo pico febril, siendo el cuadro clínico compatible con nuevo émbolo séptico, se repitieron la TAC y el ecocardiograma los cuales no se modificaron respecto a los previos; con posterioridad ha permanecido afebril y asintomático con desaparición de la astenia y ganancia de peso. Se realizo un control posterior a las diez semanas del proceso, siendo el resultado del TAC toracoabdominal: Infiltrados en ambas bases pulmonares de pequeño tamaño, compatible con atelectasias subsegmentarias.

La infección por Capnocytophaga spp desde el punto de vista clínico es más frecuente en varones y con un amplio rango de edad (2); también se ha descrito en niños (6). Puede presentar múltiples factores predisponentes para desarrollar este cuadro infeccioso, como sucede en la mayoría de los casos comunicados en la literatura, destacando el alcoholismo $(1,2,4,5)$ como sucede en nuestro caso y en los pacientes con ausencia de bazo (1-3,5); así como cualquiera de los procesos concomitantes que conlleve un proceso de inmunodepresión (procesos hematológicos como leucemias y linfomas (6), posradiación en neoplasia pulmonar, etc.). 
Se sabe que hasta un $40 \%$ de septicemias suceden en pacientes sin las condiciones predisponentes anteriormente reseñadas (5)

Los síntomas iniciales pueden ser diversos como mialgias, malestar general, vómitos, abdominalgia, disnea, cefalea, confusión y manifestaciones cutáneas (máculas, rash maculopapular o púrpura son comunes) (2,5); aunque la forma más frecuente de presentación clínica es como un síndrome febril de origen desconocido, en nuestro caso no fue así, ya que aunque si presentó fiebre, esta se acompañó en su inicio de un proceso neumónico; desarrollando posteriormente embolismos pulmonares y CID; siendo esta la complicación más frecuente que aparece en este tipo de sépsis $(2,4)(39 \%)$; seguido de meningitis $(13 \%)$, endocarditis (7) $(10 \%)$ y menos frecuentemente insuficiencia renal (9), abscesos cerebrales, exantemas cutáneos, blefaritis, celulitis, artritis, mononeuropatía y gangrena (1); incluso se ha asociado con púrpura trombótica trombocitopénica e infarto de miocardio (10). El diagnóstico se realiza al identificar el germen en los cultivos de la sangre. Su crecimiento es lento y oscila entre 3 y 11 días, dependiendo del tipo de cultivo utilizado. El antibiótico de elección es la penicilina o sus derivados. Otros antibióticos sensibles son las cefalosporinas de tercera generación, quinolonas, macrólidos, clindamicina, cloranfenicol y tetraciclinas $(1,8)$, siendo resistentes a aminoglucósidos. Sin embargo se han descrito cepas productoras de beta-lactamasas y ocasionalmente resistentes a fluoroquinolonas. El inicio del tratamiento debe ser lo más pronto posible. La mortalidad de la infección es alta, alrededor del $30 \%(4,5)$; siendo en algunas series del $50 \%(2)$; hay que tener en cuenta la situación basal comprometida de muchos de los pacientes.

\section{Calleja Subirán, J. Elizaga Corrales , D. Sánchez-Fuentes}

Servicio de Medicina Interna. Hospital Nuestra Señora de Sonsoles. Ávila. ${ }^{l}$ Complejo Hospitalario Hospital General. Segovia

1. Timothy F, Murphy, Dennis L. Kasper. En: Harrison, Fauci, Braunwld, Isselbacher, Wilson, Martin editores. Principios de Medicina Interna Vol 1(14 a edición). Mc Graw-Hill. Interamericana, 2000; 1060-61.

2. Pers C, Gahrn-Hansen B, Frederiksen W. Capnocytophaga canimorsus septicemia in Denmark, 1982-1995: review of 39 cases. Clin Infect Dis 1996; 23 (1): 71-5.

3. Mahrer S, Raik E. Capnocytophaga canimorsus septicemia associated with cat scratch. Patholofy 1992; 24 (3): 194-6.

4. Valtonen M, Lauhio A, Carlson P, Muntanen J et al. Capnocytophaga canimorsus septicemia: fifth report of a cat-associated infection and five other cases. Eur J Clin Microbiol Infect Dis 1995; 14 (6): 520-3.

5. Lion C, Escande F, Burdin JC. Capnocytophaga canimorsus infections in human: review of the literature and cases report. Eur J Epidemiol 1996; 12 (5): 521-33.

6. Kristensen B, Schonheyder HC, Peterslund NA, Rosthoj S, et al. Capnocytophaga bacteriemia in hematological patients with profound granulocytopenia. Scand J Infect Dis 1995; 27 (2): 153-5.

7. Roig PP, López MM, Martín C, Zorraquino A, Sánchez B, et al. Bacteriemia caused by Capnocytophaga sp: presentation of 2 cases, one with endocarditis. Review of the literature. An Med Interna 1996; 13 (4): 185-7.

8. Lin RD, Hsuch PR, Chang SC, Luh KT. Capnocytophaga bacteriemia: clinical features of patients and antimicrobial susceptibility of isolates. J Formos Med Assoc. 1998; 97 (1): 44-8.

9. Bateman JM, Rainford DJ, Masterton RG. Capnocytophaga canimorsus

infection and acute renal failure. J Infect 1992; 25 (1): 112-4

10. Ehrbar HU, Gubler J, Harbarth S, Hirschel B. Capnocytophaga canimorsus sepsis complicated by myocardial infarction in two patients with normal coronary arteries. Clin Infect Dis 1996; 23 (2): 335-6.

\section{Hiperhidrosis severa como forma de presentación de la acromegalia}

\section{Sr. Director:}

Las causas de la hiperhidrosis son numerosas incluyendo desde las fisiológicas hasta manifestaciones clínicas secundarias de enfermedades endocrinas (1). El aumento de la hormona de crecimiento (GH) y del factor de crecimiento insulin-like (IGF) se elevan en los síndromes acromegálicos estimulando la sudoración corporal. Aunque la hiperhidrosis es una manifestación clínica que puede aparecer en la acromegalia, no suele ser el motivo de consulta.

Paciente: Varón de 35 años, consultó en el hospital por sudoración severa y generalizada de un año de evolución que aparecía con el ejercicio mínimo, sueño, estrés y al tomar comidas ácidas. Los síntomas aparecían tanto en invierno como en verano. A la exploración clínica presentaba un aspecto atlético con $190 \mathrm{~cm}$ de estatura y un peso de $102 \mathrm{~kg}$ sin que el paciente o familiares hubieran notado ningún cambio en el aspecto físico en los últimos años. Se evidenciaba un engrosamiento de la piel periungueal en manos así como una evidente hiperhidrosis generalizada a la exploración clínica.

El resultado de la analítica practicada mostraba un incremento de los niveles basales de $\mathrm{GH}$ de 19,5 ng/ml (normal hasta $5 \mathrm{ng} / \mathrm{ml}$ ). Los tests de supresión con glucosa y octreótido fueron patológicos con ligera reducciones de los niveles de $\mathrm{GH}$ hasta $7,5 \mathrm{ng} / \mathrm{ml}$ con la administración de glucosa oral y hasta $5,5 \mathrm{ng} / \mathrm{ml}$ después de la administración de $50 \mathrm{mcg}$ de octreótido subcutáneo medidos a los 120 minutos (en test normal los niveles de GH deben caer por debajo de $2 \mathrm{ng} / \mathrm{ml}$ ). El resto de las determinaciones de laboratorio practicadas fueron normales. Una resonancia nuclear magnética (RNM) de hipófisis con y sin gadolinio mostró la presencia de un microadenoma de hipófisis de 8 milímetros de diámetro (Fig. 1).

Con estos hallazgos clínicos se realizó el diagnóstico de acromegalia como causa de la hiperhidrosis. Debido al pequeño tamaño del tumor y la buena respuesta de supresión farmacológica de la GH con octreótido se inició tratamiento con bromocriptina oral a dosis d $5 \mathrm{mg}$ dos veces al día. Después de un mes de tratamiento los niveles de GH cayeron por debajo de 2 $\mathrm{ng} / \mathrm{ml}$ con mejoría progresiva de la hiperhidrosis hasta que desapareció después de los dos meses de tratamiento. La RNM mostró una reducción de $2 \mathrm{~mm}$ en el tamaño del adenoma a los 4 meses. El paciente abandonó la medicación debido a intolerancia digestiva y la hiperhidrosis reapareció nuevamente. Se practico un tratamiento quirúrgico del microadenoma mediante

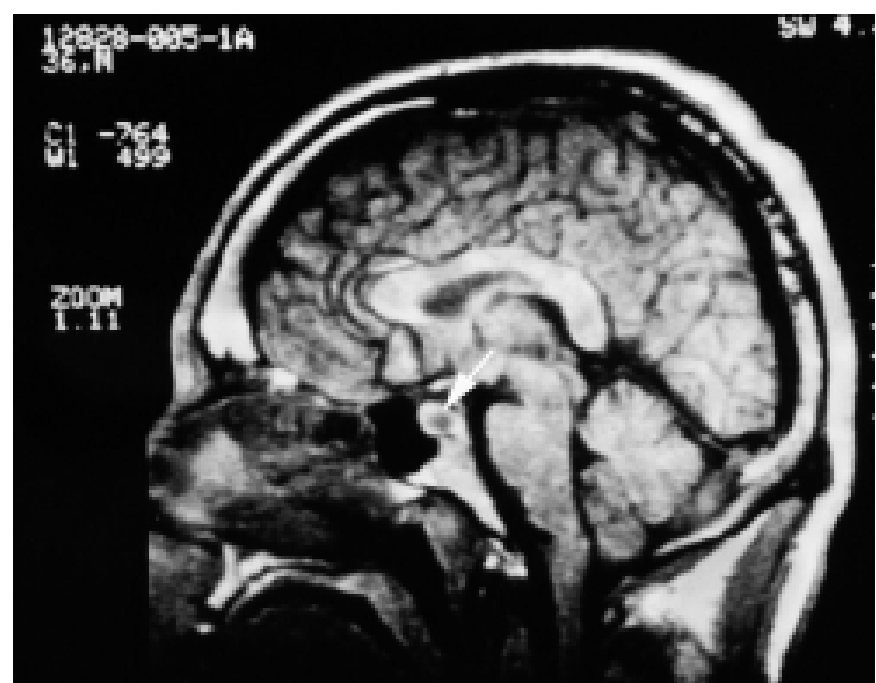

Fig. 1. Resonancia Nuclear Magnética mostrando el microadenoma hipofisario causante de la acromegalia. 
cirugía transesfenoidal con la desaparición progresiva nuevamente de la hiperhidrosis en los siguientes meses.

$\mathrm{La}$ acromegalia es una enfermedad endocrinológica causada por la elevación crónica de los niveles de GH. La etiología más frecuente es el microadenoma de hipófisis. La hiperhidrosis es una manifestación clínica frecuente en los pacientes con acromegalia que puede afectar entre el 60 y $80 \%$ de los pacientes pero habitualmente se presenta como parte del cuadro clínico general y ésta no es severa. Los pacientes notan incremento en tejidos blandos especialmente manos y pies consultando habitualmente por esta sintomatología. La sudoración excesiva no es una causa frecuente de consulta en la acromegalia.

Del mismo modo que en la acromegalia existe una hipersudoración, en los pacientes con déficit de $\mathrm{GH}$ presentan intolerancia al ejercicio con una disminución de la sensibilidad de las glándulas sudoríparas y riesgo de desarrollar hipertermia durante la actividad física y en ambientes calurosos $(2,3)$.

El interés de este caso viene dado por la importante hiperhidrosis que limitaba la actividad diaria del paciente y por lo que el paciente decide consultar, cuando aún el resto de las manifestaciones clínicas de la acromegalia eran aún poco relevantes. Este paciente tenía un microadenoma, aunque el tamaño del tumor no parece guardar relación con el tipo y la intensidad de las manifestaciones clínicas (4).

El tratamiento de la acromegalia es quirúrgico, aunque varios fármacos son muy útiles para el control de los síntomas y para reducir el tamaño del adenoma. La bromocriptina y el análogos de la somatostatina como el octreótido y más recientemente el lanreótido son eficaces y bien tolerados (5-7). Habitualmente estos fármacos se usan como tratamientos sintomáticos mientras se lleva a cabo la cirugía o cuando ésta no está indicada. Sin embargo, no había sido descrita previamente una respuesta tan buena en hiperhidrosis secundaria a acromegalia con tratamiento médico, concretamente bromocriptina.

I. Martín Suárez, F. J. Carrasco Sánchez, Ma C. Suárez
Marrero, F. Cuesta López, E. Pujol de la LLave

Servicio de Medicina Interna. Hospital Juan Ramón Jiménez. Huelva

1. Kao MC. Hyperhidrosis. J Neurosurg 1997 86: 738-739.

2. Juul A, Hjortskov N, Jepsen LT, Nielsen B, Halkjaer-Kristensen J, Vahl N, Jorgensen JO, Christiansen JS, Skakkebaek EN Growth hormone deficiency and hyperthermia during exercise: a controlled study of sixteen GH-deficient patients. J Clin Endocrinol Metab 1995; 80: 3335-3340

3. Hasan W, Cowen t, Barnett PS, et al. The sweatin aparats in grouth hormone deficiency, following treatment with $\mathrm{r}-\mathrm{hGH}$ in acromegaly. Auton Neusodci 2001; 20; 89: 100-9

4. Jadresic A, Banks LM, Child DF, Diamant L, Doyle FH, Fraser TR, Joplin GF The acromegaly syndrome. Relation between clinical features, growth hormone values and radiological characteristics of the pituitary tumours. Q J Med 1982; 51: 189-204.

5. Shi YF, Harris AG, Zhu XF, Deng JY Clinical and biochemical effects of incremental doses of the long-acting somatostatin analogue SMS 201-995 in ten acromegalic patients. Clin Endocrinol (Oxf) 1990; 32: 695-705

6. Giusti M, Ciccarelli E, Dallabonzana D, Delitala G, Faglia G, Liuzzi A, Gussoni G, Giordano Disem G Clinical results of long-term slow-release lanreotide treatment of acromegaly. Eur J Clin Invest 1997; 27: 277-284.

7. Drange MR, Melmed S. Long acting lanreotide induces clincal an biochemical remission of acromegaly caused by disseminated growth hormone-releasing hormone secreting carcinoid. J Clin Endocrinol Metab 1998; 83 (9); 3104-9. 